\title{
An Integrated Multiechelon Logistics Model with Uncertain Delivery Lead Time and Quality Unreliability
}

\author{
Ming-Feng Yang, ${ }^{1}$ Yi Lin, ${ }^{2}$ Li Hsing Ho, ${ }^{3}$ and Wei Feng Kao \\ ${ }^{1}$ Department of Transportation Science, National Taiwan Ocean University, No. 2, Beining Road, Keelung City 202, Taiwan \\ ${ }^{2}$ Graduate Institute of Industrial and Business Management, National Taipei University of Technology, No. 1, Section 3, \\ Zhongxiao E. Road, Taipei City 106, Taiwan \\ ${ }^{3}$ Department of Technology Management, Chung Hua University, No. 707, Section 2, Wufu Road, Hsinchu 30012, Taiwan \\ ${ }^{4}$ Ph.D. Program of Technology Management, Chung Hua University, No. 707, Section 2, Wufu Road, Hsinchu 30012, Taiwan
}

Correspondence should be addressed to Yi Lin; iwc3706@yahoo.com.tw

Received 29 November 2015; Revised 28 January 2016; Accepted 16 March 2016

Academic Editor: Lijun Ma

Copyright (C) 2016 Ming-Feng Yang et al. This is an open access article distributed under the Creative Commons Attribution License, which permits unrestricted use, distribution, and reproduction in any medium, provided the original work is properly cited.

\begin{abstract}
Nowadays, in order to achieve advantages in supply chain management, how to keep inventory in adequate level and how to enhance customer service level are two critical practices for decision makers. Generally, uncertain lead time and defective products have much to do with inventory and service level. Therefore, this study mainly aims at developing a multiechelon integrated just-in-time inventory model with uncertain lead time and imperfect quality to enhance the benefits of the logistics model. In addition, the Ant Colony Algorithm (ACA) is established to determine the optimal solutions. Moreover, based on our proposed model and analysis, the ACA is more efficient than Particle Swarm Optimization (PSO) and Lingo in SMEIJI model. An example is provided in this study to illustrate how production run and defective rate have an effect on system costs. Finally, the results of our research could provide some managerial insights which support decision makers in real-world operations.
\end{abstract}

\section{Introduction}

The EPQ/EOQ model has been researched for a long time; vendors can estimate the optimal economic production by using EPQ model, and buyers estimate the order quantity by using EOQ model. However, it will not lead to a win-win situation if vendors only focus on the economic production or buyers only care about the order quantity. In 1977, an integrated vendor-buyer concept has been proposed by Goyal [1]; he was the first to consider integrated inventory model. In his model, economic production and order quantity could be determined to minimize the joint total cost. He also concluded that the optimal order time interval and production cycle time could be obtained by supposing that the supplier's production cycle time was an integer of buyer's order time interval. In 1986, Banerjee [2] relaxed Goyal's [1] integrated model to develop a joint economic lot size (JELS) model; it indicated how a lot-for-lot policy works. Goyal [3] indicated an integrated model that produces a lower-joint total cost by loosening Banerjee's [2] lot-for-lot assumption. Afterwards, many researchers built their own two-echelon inventory model by combining JELS model and Goyal's [3] model.

Seo [4] proposed an improved reorder decision policy for controlling general multiechelon distribution systems. This system utilizes shared stock information. Chiu and Huang [5] addressed a multiechelon integrated JIT inventory model with a random delivery lead time. Sadeghi et al. [6] developed a constrained multivendor multiretailer single-warehouse (MV-MR-SW) supply chain, in which both the space and the annual number of orders of the central warehouse were limited. He would like to find the order quantities along with the number of shipments received by retailers and vendors such that the total inventory cost of the chain was minimized. Sana [7] proposed an integrated production-inventory model for supplier, manufacturer, and retailer, considering perfect and imperfect quality items. This model discussed the impact of business strategies such as optimal order size of raw 
materials, production rate and unit production cost, and idle times in different sectors on collaborating marketing system. Soni and Patel [8] investigated an integrated inventory model with variable production rate and price-sensitive demand rate under two-level trade credit. This study attempted to offer a best policy for retail price, replenishment cycle, and the number of shipments from the supplier to the retailer in one production run. An algorithm was also designed to determine the optimum solution of their proposed model.

Lead time usually consists of the following components: order preparation, order transit, supplier lead time, delivery time, and set-up time (Tersine [9]); this makes lead time difficult to estimate precisely. In real life, firms cannot keep inventory in adequate level if lead time is uncertain; it may cause unnecessary costs for firms. Furthermore, uncertain lead time also increases the probability of shortage; firms can not satisfy customers immediately if shortage occurs. Hence, uncertain lead time has much to do with inventory level and customer service level. Liao and Shyu [10] presented a probabilistic inventory model; they assumed that the demand follows normal distribution and the lead time consists of $n$ components, each having a different cost for reduced lead time. Ben-Daya and Raouf [11] considered both the lead time and the order quantity as decision variables based on Liao and Shyu's [10] model. Mirzapour Al-e-Hashem et al. [12] assumed an interrelationship between lead time and transportation mode; the shorter the lead times are, the more expensive transportation will be. Accordingly, they developed a stochastic programming approach to solve a multiperiod multiproduct multisite aggregate production planning problem in a green supply chain for a medium-term planning horizon under the assumption of demand uncertainty and flexible lead times. Chandra and Grabis [13] indicated that short lead time could enhance the service level and lower inventory level effectively, but short lead time also caused highly order cost.

However, demands during the lead time of the different customers are not identical, and the demand distribution for each customer is not the same either. Therefore, we cannot apply single distribution to describe the demands during the lead time. Accordingly, Wu and Tsai [14] considered the lead time demand with the mixture of normal distributions and the fixed back-order rate. Hoque [15] developed a vendorbuyer integrated production-inventory model following normal distribution of lead time. Then, he derived an optimal solution technique to the model to obtain minimum expected joint total cost that follows development of the solution algorithm.

In real life, supply chains always have many members in multiechelon; however, multiechelon inventory problems are too complicated to solve by using traditional methods. Hence, we would like to discuss some heuristic algorithm in our proposed model to solve the multiechelon problems and determine the optimal solutions. Altiparmak [16] proposed a new solution procedure based on genetic algorithms to find the set of Pareto-optimal solutions for multiobjective SCN design problem. To deal with multiobjective design problem and enable the decision makers to evaluate a greater number of alternative solutions, two different weight approaches were implemented in the proposed solution procedure. Sadeghi et al. [17] developed a biobjective vendor-managed inventory model in a supply chain with one vendor (producer) and several retailers. The aim was to find the order size, the replenishment frequency of retailers, optimal traveling tour from the vendor to retailers, and the number of machines so as the total chain cost was minimized while the system reliability of producing the item was maximized. Li et al. [18] studied the dynamic lot-sizing problem with product returns and remanufacturing (DLRR) which is to determine a production schedule of manufacturing new products and/or remanufacturing returns such that demand in each period was satisfied and the total cost (set-up cost plus holding cost of inventory) was minimized. To generate a good initial solution, they used a block-chain based method where the planning horizon was split into a chain of blocks. A block may contain either a string of manufacturing set-ups or a string of remanufacturing set-ups, or both. Given the cost of each block, an initial solution corresponding to a best combination of blocks is found by solving a shortest-path problem. Chen and Sarker [19] established an integrated optimal inventory lot-sizing and vehicle-routing model for a multisupplier single-assembler system with JIT delivery; they applied ant colony optimization to solve their model. Nia et al. [20] built a multi-item economic order quantity model with shortage under vendor-managed inventory policy in a single vendor single buyer supply chain; they proposed a new modeling to the fuzzy VMI problem with multi-items and shortage and employed three metaheuristic algorithms (ACA, GA, and DE) to solve a FNIP problem. Chen and Sarker [19] and Nia et al. [20] both considered the Ant Colony Algorithm as a metaheuristic algorithm.

In recent years, many researchers dedicated themselves to improving the integrated logistic model with the issues of uncertainties. Some related researches are listed below: Hatefi and Jolai [21] proposed a robust and reliable model for an integrated forward-reverse logistics network design, which simultaneously takes uncertain parameters and facility disruptions into account. $\mathrm{Ma}$ [22] constructed the mathematical programming model and proposed two-stage heuristic algorithm. In addition, the taboo search algorithm was designed to improve the initial solution. Hashim et al. [23] presented the study which mainly investigated a multiobjective supplier selection planning problem in fuzzy environment and the uncertain model is converted into deterministic form by the expected value measure. Q.-M. Hu and Z.-H. Hu [24] proposed a reliable closed-loop supply chain network design model, which accounts for both partial and complete facility disruptions as well as the uncertainty in the critical input data. Torabi et al. [25] considered the characteristics of the uncertainty flows. And then a stochastic mixed-integer linear programming model for designing hub-and-spoke network is established based on the capacities of spokes.

With the above discussion, we would like to establish an integrated vendor-buyer inventory model. To fit the real life, we expanded the basic integrated model to a SMEIJI model with uncertain lead time and imperfect quality. Our proposed model was too complicated to solve if we use traditional method; hence, we applied Ant Colony Algorithm 
to solve our SMEIJI model. In given example, we would like to compare ACA with other traditional methods and observe how system cost works.

\section{Fundamental Assumptions and Notations}

A serial inventory system with $S$-echelon where echelon 1 is purchasing only and echelon $S$ is manufacturing only was considered. In the inventory system we proposed, there is only one member in each echelon that plays the purchaser and manufacturer roles simultaneously except echelon 1 and echelon $S$. Notation and assumptions are defined as follows.

For member $i$ engaged in purchasing activities, where $i=$ $1,2, \ldots, S-l$, we have the following.

Decision variables are as follows:

$N_{p i}$ : number of purchase orders during $T_{m i}$ for purchasing $i$.

$n_{i}$ : number of deliveries per purchase order for purchasing $i$.

$m_{L i}$ : the maximum allowable planned delivery lead time that would not cause shortage; $m_{i}=$ $\mu L_{D i}+$ safety lead time (a real decision variable).

Parameters are as follows:

$S$ : number of echelons in a serial supply chain. $T_{p i}$ : length of a purchasing time interval for purchasing $i$ (in years).

$D_{i}$ : demand rate of purchasing $i$ (units/year).

$Q_{p i}$ : lot size per purchase order for purchasing $i$ (units/order).

$q_{i}$ : delivery lot size per shipment for purchasing $i$ (units/delivery).

$C_{s i}$ : fixed ordering cost for purchasing $i$ (\$/order).

$H_{p i}$ : holding cost per unit of purchased goods per year for purchasing $i$ (\$/unit/year).

$C_{e i}$ : ordering cost of emergency borrowing for purchasing $i$ ( $\$$ /borrowing).

$\beta_{i}$ : borrowing cost per unit per year for purchasing $i$ (\$/unit/year).

$F_{i}$ : fixed delivery cost for purchasing $i$ (\$/delivery).

$L_{d i}$ : delivery lead time from manufacturing $i+$ 1 to purchasing $i$, a nonnegative random variable following a probability distribution with expected delivery lead time $\mu L_{D i}$ and standard deviation $\sigma L_{D i}$.

$t_{i}$ : time interval between two adjacent deliveries for purchasing $i$.

$r_{i}$ : redelivery point of purchasing $i$ that is analogous to a reorder point; if stock drops to $R_{i}$, then a delivery notice is issued to manufacturer $i+1$. $x_{i}$ : screening time of $q_{i}$ amount materials that were received by purchaser $i$ (in years). $\emptyset_{i}$ : defective rate of a shipment that was received by purchaser $i$.

For member $i$ engaged in manufacturing activities, where $i=$ $1,2, \ldots, S-l$, we have the following.

Decision variables are as follows:

$N_{m i}:$ number of production runs during $T_{m i-1}$ for manufacturing $i$.

$K_{i}$ : number of deliveries per production run for manufacturing $i$.

Parameters are as follows:

$T_{m i}$ : length of a manufacturing time interval for manufacturing $i ; T_{m i}=Q_{m i} / p_{i}$ (in years).

$P_{i}$ : production rate for manufacturing $i$ (units/year).

$Q_{m i}:$ lot size per production run for manufacturing $i$ (units/run).

$C_{m i}$ : fixed set-up cost for manufacturing $i$ (\$/setup)

$H_{m i}$ : holding cost per unit of produced goods per year for manufacturing $i$ (\$/unit/year).

Additional notations will be introduced if necessary. The assumptions set in this research are as follows:

(1) We consider an integrated multiechelon supply chain which only contains a member in each echelon. The member in echelon $i$ is denoted as member $i$, where $i=1,2,3, \ldots, S$. A single product is produced by the supply chain.

(2) Except echelons 1 and $S$, purchaser and manufacturer are the two roles that each member played. Member 1 , purchasing activities only, is the lowest echelon in this serial supply chain. Member $S$ involves manufacturing activities only.

(3) Member $i$ purchases required materials from member $i+1$ and produces goods to member $i-1$ during $T_{p i}$.

(4) The demand and production rate for the product are constant over time. The demand rates of member $i$ should be less than the production rate of member $i+1$. Member $i+1$ produces the necessary quantity to satisfy the demand of member $i$.

(5) The delivery lead time $\left(L_{d i}\right)$ for member $i$ is assumed to follow a probability distribution with a density function of $L_{d i}=f\left(L_{d i}\right)$, where $0 \leq \lambda_{L i} \leq L_{d i} \leq \gamma_{L i}$ and $i=1,2, \ldots, S-1$.

(6) The time interval between two adjacent deliveries for member $i\left(t_{i}\right)$ should be longer than or equal to $\gamma_{L i}$. The delivery lot crossing makes the problem intractable, and it can be prevented by this assumption.

(7) When a delivery delay occurs, an emergency borrowing action should be touched off by member $i$ because the shortages are not allowed in JIT environment. 


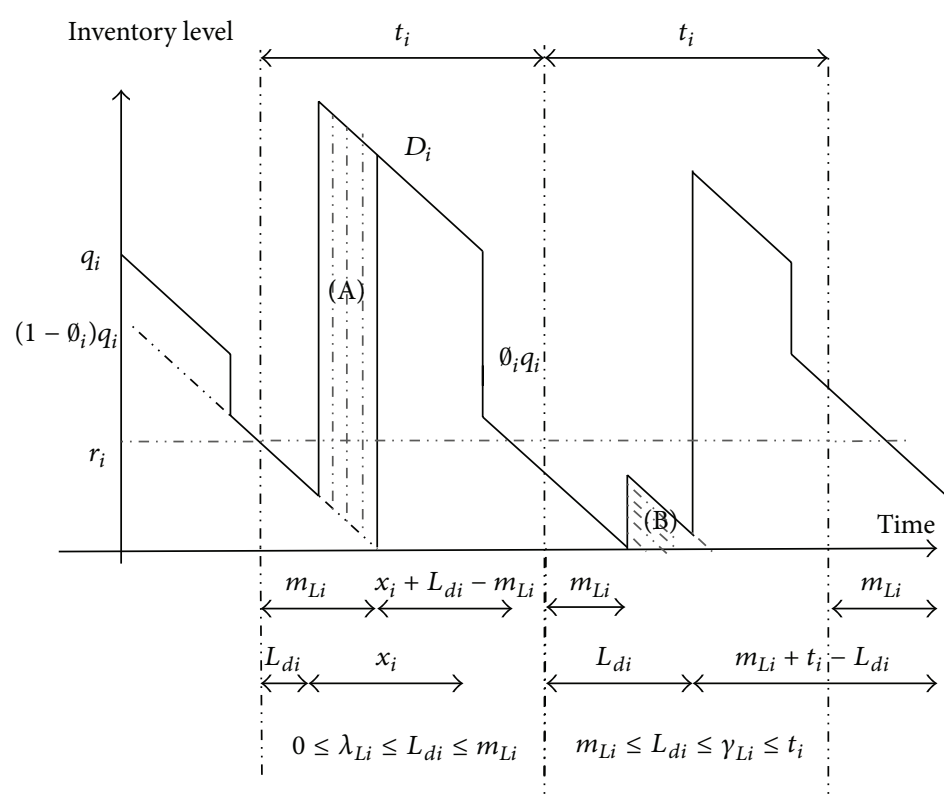

FIGURE 1: Delivery cases for the member who implements purchasing.

(8) The required time of borrowing goods from nearby supplier is ignored.

(9) A finite planning horizon for the whole serial supply chain that denoted $T_{p i}$ is considered.

(10) Defective items in a shipment of materials are received by purchaser $i$ with defective rate $\emptyset_{i}$. The number of good materials must be more than or equal to the required quantity during the screening time.

(11) The screening process is followed by the arrival of shipments with screening time $x_{i}$. The length of screening time is proportional to the number of received materials.

(12) The accumulated number of defective items that were delivered to the buyer during a production run must be less than the quantity of one delivery.

(13) When emergency borrowing happened, the materials that were borrowed and returned are all good items.

\section{Formulation of the Model}

In this integrated multiechelon JIT inventory model, the decision variables are $n_{i}$ (number of deliveries per purchase), $N_{p i}$ (number of purchase orders during $T_{p i}$ ), and $m_{L i}$ (the maximum allowable planned delivery lead time that would not cause shortage), where $i=1, \ldots, S-1 . N_{m i}$ is the number of production runs during $T_{m i}$ and $K_{i}$ are delivery times per production runs for manufacturer $i$, where $i=2, \ldots, S$. The value of these decision variables should be determined in order to minimize the joint total cost.

3.1. The Cost of Member $i$ in Purchasing Activities. From echelon1 to echelon $S-1$, members adopt JIT purchasing to replenish goods. The time buffer policy used on planned lead time $\left(m_{L i}\right)$ and emergency borrowing policy used to deal with uncertain delivery lead time. Each order lot size $Q_{p i}$ has been taken apart into $n_{i}$ small lots for delivery frequently. During the planning horizon $T_{p i}$, the total number of deliveries for member $i$ is $n_{i} \times N_{p i}$. The delivery lead time follows a probability density distribution $f\left(L_{d i}\right)$. The $\gamma_{L i}$ and $\lambda_{L i}$ are the upper bound and the lower bound of $L_{d i}$.

The costs are related to purchasing activities of member $i$ during $T_{p i}$, where $i=1, \ldots, S-1$, including ordering cost, holding cost, delivery cost, transportation carrying cost, and emergency borrowing cost. The transportation carrying cost would not be considered in this model since it is constant and does not affect any decision variables.

Owing to the uncertain delivery lead time, there are three different delivery cases: early arrival, delay arrival, and arrival on time. The screening process would be implemented when the purchaser receives a shipment of goods. The defective item would be deducted from the inventory in a single batch at the end of the purchaser's $100 \%$ screening process. Figure 1 has shown two delivery cases for the member who implements purchasing.

On the left side of Figure $1,0 \leq \lambda_{L i} \leq L_{d i} \leq m_{L i}$ means the early arrival occurs and results in unexpected holding cost. The shadow area (A) presents the unexpected extra inventory. In this case, the holding cost $\left(\mathrm{HC}_{\mathrm{A} i}\right)$ of member $i$ during $t_{i}$ is shown. The shadow area $(\mathrm{A})$ presents the unexpected extra inventory caused by early delivery, and $t_{i} q_{i}\left(1-\emptyset_{i}\right) / 2+\left(x_{i}+L_{d i}-\right.$ $\left.m_{L i}\right) q_{i} \emptyset_{i}$ represents the expected inventory.

In the right side of Figure $1, m_{L i} \leq L_{d i} \leq \gamma_{L i} \leq t_{i}$ presents the delay arrival situation. When it occurs, member $i$ should adopt emergency borrowing policy. The shadow area (B) presents the quantity of emergency borrowing. The borrowing quantity from other nearby suppliers outside the supply chain is $D_{i}\left(\gamma_{L i}-m_{L i}\right)$ units. After the delay arrival lot is received, the remand quantity of goods $D_{i}\left(\gamma_{L i}-L_{d i}\right)$ 
should be given back immediately. The borrowed and the remanded units would not be screened, and the screening time is $\left(\left(q_{i}-D_{i}\left(\gamma_{L i}-m_{L i}\right)\right) / q_{i}\right) x_{i}$ during $m_{L i} \leq L_{d i} \leq \gamma_{L i} \leq t_{i}$. The holding cost $\left(\mathrm{HC}_{\mathrm{Bi}}\right)$ and the expected borrowing cost $\left(\mathrm{EBC}_{i}\right)$ of member $i$ during $t_{i}$ are shown. The holding cost $\left(\mathrm{HC}_{\mathrm{B} i}\right)$ involves the normal holding cost and the emergency borrowing holding cost.

The unexpected extra inventory of shadow area (A) due to the early arrivals is as follows:

$$
\begin{aligned}
& \mathrm{HC}_{\mathrm{A} i}=H_{p i}\left[q_{i}\left(m_{L i}-L_{d i}\right)+\frac{t_{i} q_{i}\left(1-\emptyset_{i}\right)}{2}\right. \\
& \left.+\left(x_{i}+L_{d i}-m_{L i}\right) q_{i} \emptyset_{i}\right]=D_{i} H_{p i}\left[t_{i}\left(m_{L i}-L_{d i}\right)\right. \\
& \left.+\frac{t_{i} x_{i} \emptyset_{i}}{1-\emptyset_{i}}+\frac{t_{i}^{2}}{2}\right] .
\end{aligned}
$$

The emergency borrowing holding cost due to delay arrivals is as follows:

$$
D_{i} H_{p i}\left[\frac{\left[\left(r_{L i}-L_{d i}\right)+\left(r_{L i}-m_{L i}\right)\right]\left(L_{d i}-m_{L i}\right)}{2}\right] .
$$

Normal holding cost without early or delay arrivals is as follows:

$$
\begin{aligned}
& D_{i} H_{p i}\left[\frac{\left(t_{i}+L_{L i}-L_{d i}\right)^{2}}{2}\right. \\
& \left.+\left(\frac{t_{i}-\left(r_{L i}-m_{L i}\right)\left(1-\emptyset_{i}\right)}{1-\emptyset_{i}}\right) x_{i} \emptyset_{i}\right], \\
& \mathrm{HC}_{\mathrm{B} i}=H_{p i}[(B)+(C)]=D_{i} H_{p i}\left[\left(r_{L i}-m_{L i}\right)\right. \\
& \left.+\left(L_{d i}-m_{L i}\right)\right]+t_{i}\left(m_{L i}-L_{d i}\right)+\frac{t_{i}^{2}}{2}-\left(r_{L i}-m_{L i}\right) \\
& \quad \cdot\left(x_{i} \emptyset_{i}\right)+\frac{t_{i} x_{i} \emptyset_{i}}{1-\emptyset_{i}} .
\end{aligned}
$$

Now, we combine (1) and (3) to form the expected holding cost $\left(\mathrm{EHC}_{i}\right)$ of member $i$ as follows:

$$
\begin{aligned}
& \mathrm{EHC}_{i}=\int_{\lambda_{L i}}^{m_{L i}} \mathrm{HC}_{\mathrm{Ai}} f\left(L_{d i}\right) d L_{d i} \\
& +\int_{m_{L i}}^{r_{L i}} \mathrm{HC}_{\mathrm{Bi}} f\left(L_{d i}\right) d L_{d i}=D_{i} H_{p i}\left[t _ { i } \left(m_{L i}\right.\right. \\
& \left.-L_{d i}\right)+\frac{t_{i}^{2}}{2}+\frac{t_{i} x_{i} \emptyset_{i}}{1-\emptyset_{i}}+\left(r_{L i}-m_{L i}\right) \\
& \cdot\left[\int_{m_{L i}}^{r_{L i}}\left(L_{d i}-m_{L i}\right) f\left(L_{d i}\right) d L_{d i}\right. \\
& \left.\left.-\left(x_{i} \emptyset_{i}\right) \int_{m_{L i}}^{r_{L i}} f\left(L_{d i}\right) d L_{d i}\right]\right] .
\end{aligned}
$$

The expected borrowing cost $\left(\mathrm{EBC}_{i}\right)$ is as follows:

$$
\begin{aligned}
\mathrm{EBC}_{i}= & C_{e i} \int_{m_{L i}}^{r_{L i}} f\left(L_{d i}\right) d L_{d i} \\
& +\beta_{i} \int_{m_{L i}}^{r_{L i}} D_{i}\left(r_{L i}-m_{L i}\right) f\left(L_{d i}\right) d L_{d i} \\
= & {\left[C_{e i}+\beta_{i} D_{i}\left(r_{L i}-m_{L i}\right)\right] \int_{m_{L i}}^{r_{L i}} f\left(L_{d i}\right) d L_{d i} . }
\end{aligned}
$$

The $\mathrm{EBC}_{i}$ only occurs at time interval $\left[\gamma_{L i}, m_{L i}\right]$. $C_{e i} \int_{m_{L i}}^{r_{L i}} f\left(L_{d i}\right) d L_{d i}$ means the ordering cost of emergency borrowing, and $\beta_{i} \int_{m_{L i}}^{r_{L i}} D_{i}\left(r_{L i}-m_{L i}\right) f\left(L_{d i}\right) d L_{d i}$ presents the excepted cost of borrowed units.

During the purchasing time interval $\left(T_{p i}\right)$ of each member, it has $N_{p i}$ purchasing orders, $n_{i} N_{p i}$ delivery receiving times, $n_{i} N_{p i} F_{i}$ delivery cost, and $N_{p i} C_{s i}$ ordering cost. Thus, the expected cost $\left(\mathrm{EP}_{c i}\right)$ of member $i$ in purchasing activities is shown as follows:

$$
\begin{aligned}
& \mathrm{EC}_{p i}\left(n_{i}, N_{p i}, m_{L i}\right)=\text { holding cost } \\
& + \text { emergency borrowing cost }+ \text { ordering cost } \\
& + \text { delivery cost }=n_{i} N_{p i}\left[\mathrm{EHC}_{i}+\mathrm{EBC}_{i}\right]+N_{p i} C_{s i} \\
& +n_{i} N_{p i} F_{i}=n_{i} N_{p i} D_{i} H_{p i}\left[t_{i}\left(m_{L i}-L_{d i}\right)+\frac{t_{i}^{2}}{2}\right. \\
& \left.+\frac{t_{i} x_{i} \emptyset_{i}}{1-\emptyset_{i}}+\left(r_{L i}-m_{L i}\right)\right] \\
& +\left[\int_{m_{L i}}^{r_{L i}}\left(L_{d i}-m_{L i}\right) f\left(L_{d i}\right) d L_{d i}\right. \\
& \left.\quad-\left(x_{i} \emptyset_{i}\right) \int_{m_{L i}}^{r_{L i}} f\left(L_{d i}\right) d L_{d i}\right]+n_{i} N_{p i}\left[C_{e i}\right. \\
& \left.+\beta_{i} D_{i}\left(r_{L i}-m_{L i}\right)\right] \int_{m_{L i}}^{r_{L i}} f\left(L_{d i}\right) d L_{d i}+F_{i}+N_{p i} C_{s i} .
\end{aligned}
$$

3.2. The Cost of Member i Related to Manufacturing Activities. In this model, member $i+1$ adopts JIT manufacturing to produce goods to member $i$. There are $N_{m i+1}$ production runs during $T_{p i}$. The start time of each production can be determined by counting backward $q_{i-1} / P_{i}$ time units when the first delivery lot is delivered. The average inventory of goods produced by member $i$ per production run is illustrated by Figure 2, and we can determine this by calculating the cumulative time-weighted production quantity (1) (the trapezoid area) minus the cumulative time-weighted delivery quantity (2) (the ladder area).

Calculating the cumulative time-weighted production quantity of member $i$ per production run is equal to calculating a square measure of trapezoid area. Another way to calculate the cumulative time-weighted production quantity 


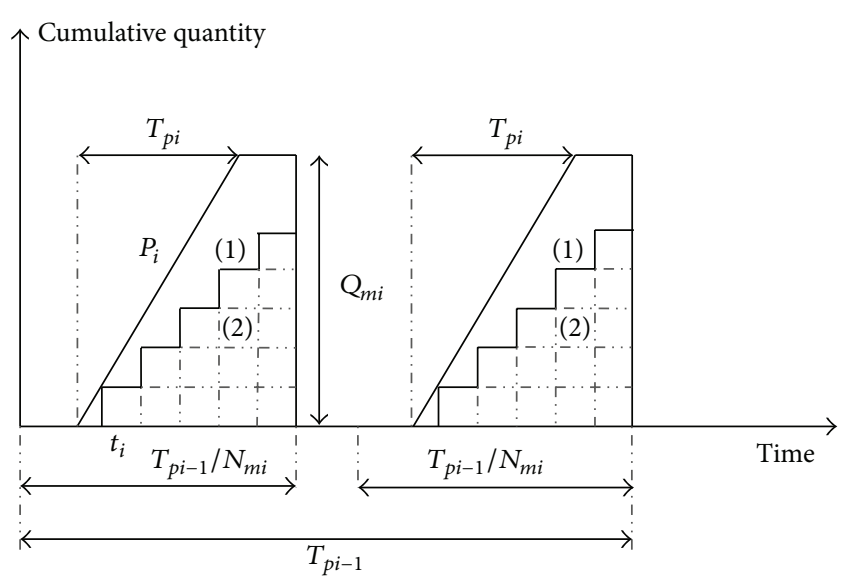

FIgURE 2: Average inventory of goods produced by member $i$ per production run.

(1) is subtracting the triangle area from the rectangle area as follows:

$$
\begin{aligned}
(1) & =\left[\frac{T_{p i-1}}{N_{m i}}-\left(t_{i-1}-\frac{q_{i-1}}{p_{i}}\right)\right]\left(\frac{D_{i-1} T_{p i-1}}{N_{m i}}\right) \\
& -\frac{1}{2}\left(\frac{D_{i-1} T_{p i}}{P_{i} N_{m i}}\right)\left(\frac{D_{i-1} T_{p i-1}}{N_{m i}}\right)=\left(\frac{T_{p i-1}}{N_{m i}}\right)^{2} D_{i-1}\left[\frac{1}{2}\right. \\
& \left.+\frac{\emptyset_{i-1}}{K_{i}\left(1-\emptyset_{i}\right)}+\left(\frac{1}{2}-\frac{1}{K_{i}\left(1-\emptyset_{i-1}\right)}\right)\left(1-\frac{D_{i-1}}{P_{i}}\right)\right] .
\end{aligned}
$$

During each production run of member $i$, there are $K_{i}$ deliveries and $q_{i}$ units of goods delivered per shipment. The time interval between two adjacent deliveries for member $i\left(t_{i}\right)$ should be longer than or equal to $\gamma_{L i}$. Hence, the cumulative time-weighted delivery quantity (2) of member $i$ per production run is

$$
\begin{aligned}
(2) & =\left(\sum_{l}^{K_{i-1}} l\right) t_{i-1} q_{i-1}=\left(1+2+\cdots+\left(K_{i-1}\right)\right) t_{i-1} q_{i-1} \\
& =\left(\frac{T_{p i-1}}{N_{m i}}\right)^{2} D_{i-1}\left[\frac{1}{2} \frac{K_{i-1}}{K_{i}\left(1-\emptyset_{i-1}\right)}\right] .
\end{aligned}
$$

Consequently, the average inventory $\left(\mathrm{AI}_{i}\right)$ of member $i$ during $T_{p i-1}$ can be calculated by subtracting area (2) from area (1) as follows:

$$
\begin{aligned}
\mathrm{AI}_{i} & =N_{m i}\{(1)-(2)\}=N_{m i}\left\{( \frac { T _ { p i - 1 } } { N _ { m i } } ) ^ { 2 } D _ { i - 1 } \left[\frac{1}{2}\right.\right. \\
& \left.\left.+\frac{\emptyset_{i}}{K_{i}\left(1-\emptyset_{i}\right)}+\left(\frac{1}{2}-\frac{1}{K_{i}\left(1-\emptyset_{i-1}\right)}\right)\left(1-\frac{D_{i}}{P_{i}}\right)\right]\right\} \\
& -\frac{T_{p i-1}}{N_{m i}} D_{i-1}\left[\frac{1}{2} \frac{K_{i-1}}{K_{i}\left(1-\emptyset_{i-1}\right)}\right]=\left(\frac{T_{p i-1}^{2}}{N_{m i}}\right)
\end{aligned}
$$

$$
\begin{aligned}
& \cdot D_{i-1}\left[\frac{1}{2}\left(\frac{K_{i}+\emptyset_{i-1}-1}{K_{i}\left(1-\emptyset_{i}\right)}\right)+\left(\frac{1}{2}-\frac{1}{K_{i}\left(1-\emptyset_{i-1}\right)}\right)\right. \\
& \left.\cdot\left(1-\frac{D_{i-1}}{P_{i}}\right)\right] .
\end{aligned}
$$

Thus, the production cost of member $i\left(\mathrm{EC}_{m i}\right)$ during $T_{p i}$ is

$$
\begin{gathered}
\mathrm{EC}_{m i}\left(N_{m i} K_{i}\right)=N_{m i} C_{m i}+H_{m i} \mathrm{AI}_{i}=N_{m i} C_{m i} \\
+H_{m i}\left\{( \frac { T _ { p i - 1 } ^ { 2 } } { N _ { m i } } ) D _ { i - 1 } \left[\frac{1}{2}\left(\frac{K_{i}+\emptyset_{i-1}-1}{K_{i}\left(1-\emptyset_{i}\right)}\right)\right.\right. \\
\left.\left.+\left(\frac{1}{2}-\frac{1}{K_{i}\left(1-\emptyset_{i-1}\right)}\right)\left(1-\frac{D_{i-1}}{P_{i}}\right)\right]\right\} .
\end{gathered}
$$

3.3. The Joint Cost of Member $i$ in Purchasing Activities and Member $i+1$ in Manufacturing Activities. With the above discussion, we have inferred the expected cost of member $i$ in purchasing and manufacturing, respectively. Therefore, the joint cost of member $i$ in purchasing activities and member $i+1$ in manufacturing activities can be obtained easily. We substituted $n_{i} N_{p i}=K_{i+1} N_{m i+1}$ into (6) and (10) and gained the joint cost of members $i$ and $i+1$ as

$$
\begin{aligned}
& C_{i, i+1}\left(N_{p i}, m_{L i}, N_{m i+1}, K_{i+1}\right)=\mathrm{EC}_{p i}+\mathrm{EC}_{m i+1} \\
& =N_{m i+1} K_{i+1}\left[\mathrm{EHC}_{i}+\mathrm{EBC}_{i}\right]+N_{p i} C_{p i} \\
& +N_{m i+1} C_{m i+1}+H_{m i+1} \mathrm{AI}_{i+1} \\
& =N_{m i+1} K_{i+1}\left\{D_{i} H_{p i}\left[t_{i}\left(m_{L i}-\mu_{L d i}\right)\right]+\frac{t_{i}^{2}}{2}\right. \\
& +\frac{t_{i} x_{i} \emptyset_{i}}{1-\emptyset_{i}}+\left(r_{L i}-m_{L i}\right) \\
& \cdot\left[\int_{m_{L i}}^{r_{L i}}\left(L_{d i}-m_{L i}\right) f\left(L_{d i}\right) d L_{d i}\right. \\
& \left.\left.-\left(x_{i} \emptyset_{i}\right) \int_{m_{L i}}^{r_{L i}} f\left(L_{d i}\right) d L_{d i}\right]\right\}+\left[C_{e i}+\beta_{i} D_{i}\left(r_{L i}\right.\right. \\
& \left.\left.-m_{L i}\right)\right]\left[\int_{m_{L i}}^{r_{L i}} f\left(L_{d i}\right) d L_{d i}+F_{i}\right]+N_{p i} C_{s i} \\
& +N_{m i} C_{m i}+H_{m i}\left\{\left(\frac{T_{p i-1}^{2}}{N_{m i}}\right)\right. \\
& \cdot D_{i-1}\left[\frac{1}{2}\left(1-\frac{K_{i}+\emptyset_{i-1}-1}{K_{i}\left(1-\emptyset_{i}\right)}\right)\right. \\
& \left.\left.+\left(\frac{1}{2}-\frac{1}{K_{i}\left(1-\emptyset_{i-1}\right)}\right)\left(1-\frac{D_{i-1}}{P_{i}}\right)\right]\right\} .
\end{aligned}
$$


Substitute $t_{i}=T_{p i} / K_{i+1} N_{m i+1}$ into (11a). Consider

$$
\begin{aligned}
& C_{i, i+1}\left(N_{p i}, m_{L i}, N_{m i+1}, K_{i+1}\right)=v_{i} T_{p i}\left(m_{L i}-\mu_{L d i}\right) \\
& +v_{i} T_{p i} x_{i} \rho_{i}+\frac{T_{p i}^{2}}{K_{i+1} N_{m i+1}}\left(\Omega_{i}-\frac{H_{m i+1} D_{i} K_{i+1} \rho_{i}}{2}\right) \\
& \quad+\frac{T_{p i}^{2}}{N_{m i+1}} \theta_{i}+K_{i+1} N_{m i+1}\left[\left(r_{L i}-m_{L i}\right)\right. \\
& \quad \cdot v_{i} \int_{m_{L i}}^{r_{L i}}\left(L_{d i}-m_{L i}\right) f\left(L_{d i}\right) d L_{d i} \\
& \left.\quad+\varepsilon_{i} \int_{m_{L i}}^{r_{L i}} f\left(L_{d i}\right) d L_{d i}+F_{i}\right]+N_{p i} C_{s i} \\
& +N_{m i+1} C_{m i+1},
\end{aligned}
$$

where

$$
\begin{aligned}
v_{i} & =H_{p i} D_{i}, \\
\rho_{i} & =\frac{\emptyset_{i}}{1-\emptyset_{i}}, \\
\Omega_{i} & \\
& =\frac{D_{i}}{2}\left[H_{p i}+H_{m i+1}\left(1-\left(\frac{2}{1-\emptyset_{i}}\right)\left(1-\frac{D_{i}}{P_{i+1}}\right)\right)\right], \\
\varepsilon_{i} & =C_{e i}+\left(\beta_{i} D_{i}-v_{i} x_{i} \emptyset_{i}\right)\left(r_{L i}-m_{L i}\right), \\
\theta_{i} & =\frac{H_{m i+1} D_{i}}{2}\left(1-\frac{D_{i}}{P_{i+1}}\right) .
\end{aligned}
$$

Since $T_{p i}=Q_{m i-1} / P_{i}=\left(D_{i-1} / N_{m i+1} P_{i}\right) T_{p i-1}, T_{p i}$ can be expressed further as

$$
T_{p i}=\left(\frac{\varphi_{i}}{\prod_{l=1}^{i} N_{m l}}\right) T_{p 1}
$$

where

$$
\varphi_{i}= \begin{cases}1 & \text { if } i=1 \\ \prod_{l=2}^{i}\left(\frac{D_{i-1}}{P_{i}}\right) & \text { if } i=2,3, \ldots, S-1 .\end{cases}
$$

All the $T_{p i}$ in function (11b) could be replaced as follows:

$$
\begin{aligned}
& C_{i, i+1}\left(N_{p i}, m_{L i}, N_{m i+1}, K_{i+1}\right)=v_{i}\left(\frac{\varphi_{i}}{\prod_{l=1}^{i} N_{m l}}\right) \\
& \cdot T_{p 1}\left(m_{L i}-\mu_{L d i}\right)+v_{i}\left(\frac{\varphi_{i}}{\prod_{l=1}^{i} N_{m l}}\right) T_{p 1} x_{i} \rho_{i} \\
& +\frac{\left(\varphi_{i} / \prod_{l=1}^{i} N_{m l}\right) T_{p 1}^{2}}{K_{i+1} N_{m i+1}}\left(\Omega_{i}-\frac{H_{m i+1} D_{i} K_{i+1} \rho_{i}}{2}\right) \\
& +\frac{\left(\varphi_{i} / \prod_{l=1}^{i} N_{m l}\right) T_{p 1}^{2}}{N_{m i+1}} \theta_{i} \\
& +K_{i+1} N_{m i+1}\left[\left(r_{L i}-m_{L i}\right)\right. \\
& +v_{i} \int_{m_{L i}}^{r_{L i}}\left(L_{d i}-m_{L i}\right) f\left(L_{d i}\right) d L_{d i} \\
& \left.+\varepsilon_{i} \int_{m_{L i}}^{r_{L i}} f\left(L_{d i}\right) d L_{d i}+F_{i}\right]+N_{p i} C_{s i} \\
& +N_{m i+1} C_{m i+1} .
\end{aligned}
$$

There are $N_{m i+1}$ purchasing times of member $i+1$ during $T_{p i}$. According to (11c), the joint total cost function including purchasing and manufacturing activities of the serial $S$ echelon integrated JIT inventory model is presented in

$$
\begin{aligned}
& \sum_{i=1}^{S-1}\left\{v_{i} \varphi_{i} T_{p 1}\left(m_{L i}-\mu_{L d i}\right)+v_{i} \varphi_{i} T_{p 1} x_{i} \rho_{i}\right. \\
& +\frac{\left(\varphi_{i} T_{p 1}\right)^{2}}{K_{i+1} \prod_{l=1}^{i} N_{m l}}\left(\Omega_{i}-\frac{H_{m i+1} D_{i} K_{i+1} \rho_{i}}{2}\right) \\
& +\frac{T_{p 1}^{2}}{\prod_{l=1}^{i} N_{m l}} \theta_{i}+\left(\prod_{l=1}^{i} N_{m l}\right) K_{i+1} N_{m i+1}\left[\left(r_{L i}-m_{L i}\right)\right. \\
& \cdot v_{i} \int_{m_{L i}}^{r_{L i}}\left(L_{d i}-m_{L i}\right) f\left(L_{d i}\right) d L_{d i} \\
& \left.+\varepsilon_{i} \int_{m_{L i}}^{r_{L i}} f\left(L_{d i}\right) d L_{d i}+F_{i}\right]+\left(\prod_{l=1}^{i} N_{m l}\right) N_{p i} C_{s i} \\
& \left.+\left(\prod_{l=1}^{i} N_{m l}\right) C_{m i+1}\right\}
\end{aligned}
$$

The delivery time constrains $0 \leq \lambda_{L i} \leq m_{L i} \leq \gamma_{L i} \leq$ $t_{i}, i=1,2, \ldots, S-1$, and variables constrains are considered in the inventory model. Eventually, the $S$-echelon integrated JIT model can be expressed as

Minimize $J C_{1, S}\left(N_{p}, m_{L}, N_{m}, K\right)$

$$
=\sum_{i=1}^{S-1}\left\{v_{i} \varphi_{i} T_{p 1}\left(m_{L i}-\mu_{L d i}\right)+v_{i} \varphi_{i} T_{p 1} x_{i} \rho_{i}+\frac{\left(\varphi_{i} T_{p 1}\right)^{2}}{K_{i+1} \prod_{l=1}^{i} N_{m l}}\left(\Omega_{i}-\frac{H_{m i+1} D_{i} K_{i+1} \rho_{i}}{2}\right)+\frac{T_{p 1}^{2}}{\prod_{l=1}^{i} N_{m l}} \theta_{i}\right.
$$




$$
\begin{aligned}
& +\left(\prod_{l=1}^{i} N_{m l}\right) K_{i+1} N_{m i+1}\left[\left(r_{L i}-m_{L i}\right) v_{i} \int_{m_{L i}}^{r_{L i}}\left(L_{d i}-m_{L i}\right) f\left(L_{d i}\right) d L_{d i}+\varepsilon_{i} \int_{m_{L i}}^{r_{L i}} f\left(L_{d i}\right) d L_{d i}+F_{i}\right] \\
& \left.+\left(\prod_{l=1}^{i} N_{m l}\right) N_{p i} C_{s i}+\left(\prod_{l=1}^{i} N_{m l}\right) C_{m i+1}\right\} \\
\text { Subject to } \quad 0 \leq & \lambda_{L i} \leq m_{L i} \leq \gamma_{L i} \leq t_{i} \quad \text { for } i=1,2, \ldots, S-1 \\
& K_{i+1} \leq \frac{1}{\emptyset_{i}}-1 \\
& N_{p i}, K_{i+1}, N_{m i+1} \text { are all integers, for } i=1,2, \ldots, S-1 .
\end{aligned}
$$

\section{Numeral Experiment and Analysis}

In this section, a numeral experiment is proposed based on proper parameter settings. All results in this research were performed on a PC. Programs were written in Matlab 2012b. An efficiency comparison between Lingo, PSO algorithm, and Ant Colony Algorithm was proposed as well. Furthermore, we would like to discuss how production runs and defective rate influences whole system cost.
4.1. Experiment Results of Ant Colony Algorithm, Particle Swarm Optimization, and Lingo. With appropriate parameters settings, we may build a 7-echelon supply chain integrated JIT inventory model with uncertain delivery lead time and unreliable quality of received items. Assume the purchasing time interval for first purchaser in years $\left(T_{p 1}\right)$ is 1.2 years. The relevant data of purchasing and manufacturing activities are shown in Tables 1 and 2.

The objective function and constraint function are shown below. Consider

$$
\begin{aligned}
& J C_{1, S}\left(N_{p}, m_{L}, N_{m}, K\right) \\
& =\sum_{i=1}^{S-1}\left\{v_{i} \varphi_{i} T_{p 1}\left(m_{L i}-\mu_{L d i}\right)+v_{i} \varphi_{i} T_{p 1} x_{i} \rho_{i}+\frac{\left(\varphi_{i} T_{p 1}\right)^{2}}{K_{i+1} \prod_{l=1}^{i} N_{m l}}\left(\Omega_{i}-\frac{H_{m i+1} D_{i} K_{i+1} \rho_{i}}{2}\right)+\frac{T_{p 1}^{2}}{\prod_{l=1}^{i} N_{m l}} \theta_{i}\right. \\
& +\left(\prod_{l=1}^{i} N_{m l}\right) K_{i+1} N_{m i+1}\left[\left(r_{L i}-m_{L i}\right) v_{i} \int_{m_{L i}}^{r_{L i}}\left(L_{d i}-m_{L i}\right) f\left(L_{d i}\right) d L_{d i}+\varepsilon_{i} \int_{m_{L i}}^{r_{L i}} f\left(L_{d i}\right) d L_{d i}+F_{i}\right] \\
& \left.+\left(\prod_{l=1}^{i} N_{m l}\right) N_{p i} C_{s i}+\left(\prod_{l=1}^{i} N_{m l}\right) C_{m i+1}\right\} \\
& \text { Subject to } 0 \leq \lambda_{L i} \leq m_{L i} \leq \gamma_{L i} \leq t_{i} \text { for } i=1,2, \ldots, S-1 \\
& K_{i+1} \leq \frac{1}{\emptyset_{i}}-1 \\
& N_{p i}, K_{i+1}, N_{m i+1} \text { are all integers, for } i=1,2, \ldots, S-1 \text {. }
\end{aligned}
$$

The goal of this research is to find out the optimal solution of the 7-echelon inventory model via the above functions and ACA and compare the efficiency between Lingo, ACA, and PSO.

As Table 3 shows, though all the three methods were capable of finding the optimal solution for SMEIJI problem, ACA was obviously better than PSO and Lingo in efficiency. ACA has shown fastest CPU searching time and least average iterations among three methods.

4.2. Experiments of Performance and S-Echelon. In this section, we would like to discuss the relationship between CPU searching time and echelon number among three methods; we also discussed the relationship between average iterations and echelon number.

As Figure 3 shows, the CPU searching time would increase with the number of echelons due to the complicated calculation. However, because of the well-organized constraint function and good initial solution, ACA still kept lower CPU searching time than the other two methods. On the other hand, Figure 4 shows that ACA's average iterations were the least among three methods. At the beginning of the multiechelon, all the three algorithms need a great amount of iterations to search the optimal solution. After calculating 
TABLE 1: The relevant data of purchasing activities.

\begin{tabular}{lcccccccccccc}
\hline & & \multicolumn{1}{c}{ Purchasing activity } & \multicolumn{1}{c}{} \\
Echelon & $D_{i}$ & $C_{s i}$ & $H_{p i}$ & $C_{e i}$ & $\beta_{i}$ & $\lambda_{L i}$ & $\gamma_{L i}$ & $\mu_{L d i}$ & $\sigma_{L d i}$ & $F_{i}$ & $X_{i}$ & $\emptyset_{i}$ \\
\hline 1 & $18 \mathrm{w}$ & 25 & 2.8 & 29 & 3.2 & 0.005 & 0.015 & 0.009 & 0.002 & 70 & 0.005 & 0.03 \\
2 & $20 \mathrm{w}$ & 28 & 2.2 & 32 & 2.6 & 0.004 & 0.01 & 0.0064 & 0.0012 & 50 & 0.003 & 0.01 \\
3 & $24 \mathrm{w}$ & 32 & 1.7 & 38 & 2.1 & 0.003 & 0.009 & 0.0054 & 0.0012 & 48 & 0.003 & 0.04 \\
4 & $30 \mathrm{w}$ & 36 & 1.2 & 42 & 1.6 & 0.004 & 0.012 & 0.0072 & 0.0016 & 55 & 0.004 & 0.05 \\
5 & $35 \mathrm{w}$ & 35 & 0.8 & 37 & 1.2 & 0.006 & 0.016 & 0.01 & 0.002 & 80 & 0.005 & 0.01 \\
6 & $40 \mathrm{w}$ & 38 & 0.6 & 40 & 0.9 & 0.004 & 0.014 & 0.008 & 0.002 & 65 & 0.005 & 0.02 \\
7 & - & - & - & - & - & - & - & - & - & - & - & - \\
\hline
\end{tabular}

TABLE 2: The relevant data of manufacturing activities.

\begin{tabular}{lccc}
\hline \multicolumn{4}{c}{ Manufacturing activities } \\
Echelon & $P_{i}$ & $C_{m i}$ & $H_{m i}$ \\
\hline 1 & - & - & - \\
2 & 200000 & 280 & 2.5 \\
3 & 240000 & 200 & 1.9 \\
4 & 300000 & 320 & 1.4 \\
5 & 350000 & 360 & 1.0 \\
6 & 400000 & 380 & 0.9 \\
7 & 450000 & 420 & 0.5 \\
\hline
\end{tabular}

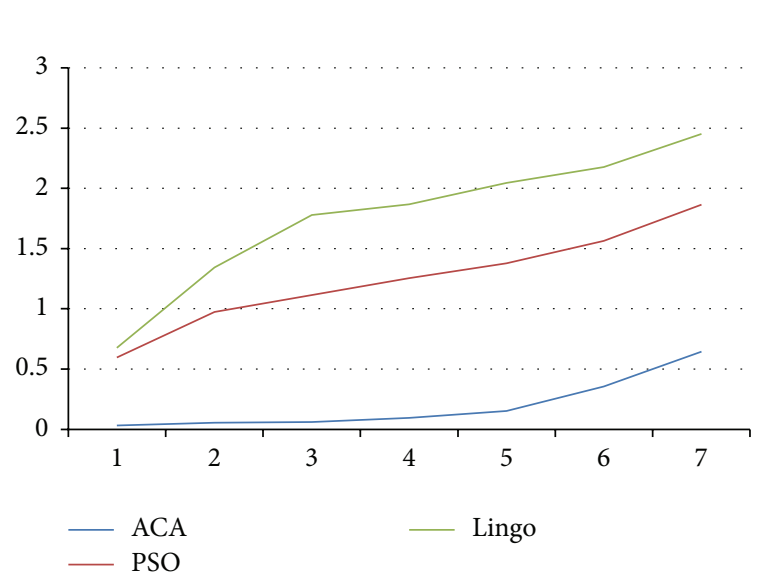

FIGURE 3: Experiment results of CPU time and echelon number.

repeatedly, the trend of the average iterations would come flat without extreme variety.

Nevertheless, although ACA seems better than the other two algorithms, we could not ensure that the performance would still be great when applied to higher echelon inventory model. Hence, a 15-echelon model has proposed to observe the performance again. The following table displayed the parameters of 15-echelon model.

To evaluate the performance of ACA, PSO, and Lingo for the 15-echelon inventory model, we applied the parameters in Tables 4 and 5 to solve the 15 -echelon inventory problem.

According to Table 6, all three algorithms were still able to find out the optimal solution of the 15-echelon inventory model. Once the echelon increases, the complexity of the

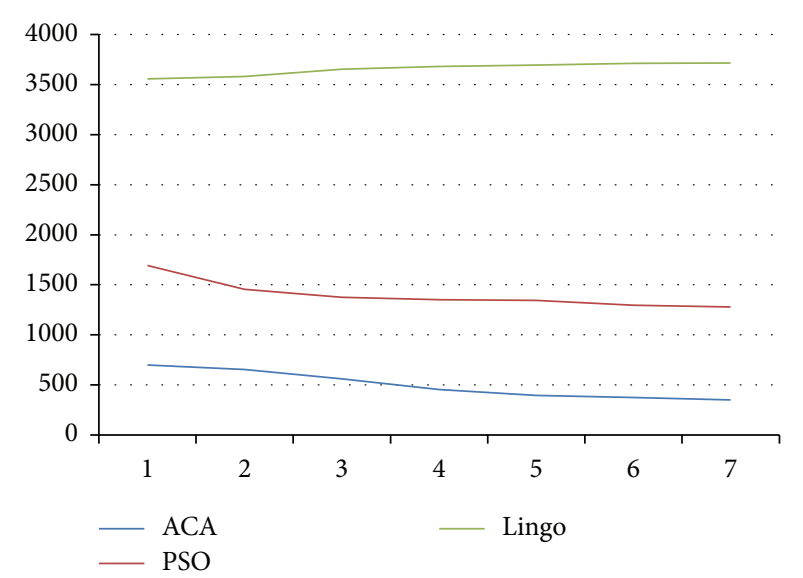

FIGURE 4: Experiment results of average iterations and echelon number.

model increases as well. However, the performance of ACA was still better than the other two algorithms.

There are several advantages of ACA as follows:

(1) Applying the positive and negative feedback enables the process of searching optimization to converge at the end, which means the results would close to the optimal solutions gradually.

(2) Every single ant is able to change the surrounding environment through releasing pheromone and being conscious of the variety of environment which makes them communicate with each other.

(3) Due to distributed computing, all the individuals start to calculate simultaneously during the searching process, which enhances the efficiency of the calculation ability.

(4) For the proposed algorithm, it is difficult to stick in the partial optimization; instead, it is always easy to find the best solution.

To sum up, ACA was proposed to solve the complicated mathematical problem; we also have proved that ACA was more efficient than PSO and Lingo. These are the new major contributions of the present paper.

4.3. The Sensitive Analysis of SMEIJI. In this section, the number of production runs $N_{m i}$ and the defective rate of 
TABLE 3: Comparisons between three methods in SMEIJI problem.

\begin{tabular}{|c|c|c|c|c|c|c|c|c|c|c|c|c|}
\hline \multirow{2}{*}{ Echelon } & \multicolumn{4}{|c|}{ ACA } & \multicolumn{4}{|c|}{ PSO } & \multicolumn{4}{|c|}{ Lingo } \\
\hline & $N_{p i}$ & $m_{L i}$ & $K_{i}$ & $N_{m i}$ & $N_{p i}$ & $m_{L i}$ & $K_{i}$ & $N_{m i}$ & $N_{p i}$ & $m_{L i}$ & $K_{i}$ & $N_{m i}$ \\
\hline 1 & 1 & 0.0147 & - & - & 1 & 0.0147 & - & - & 1 & 0.0147 & - & - \\
\hline 2 & 1 & 0.00987 & 11 & 1 & 1 & 0.00987 & 11 & 1 & 1 & 0.00987 & 11 & 1 \\
\hline 3 & 1 & 0.00889 & 13 & 1 & 1 & 0.00889 & 13 & 1 & 1 & 0.00889 & 13 & 1 \\
\hline 4 & 1 & 0.01184 & 11 & 1 & 1 & 0.01184 & 11 & 1 & 1 & 0.01184 & 11 & 1 \\
\hline 5 & 1 & 0.01571 & 8 & 1 & 1 & 0.01571 & 8 & 1 & 1 & 0.01571 & 8 & 1 \\
\hline 6 & 1 & 0.01378 & 5 & 1 & 1 & 0.01378 & 5 & 1 & 1 & 0.01378 & 5 & 1 \\
\hline 7 & - & - & 5 & 1 & - & - & 5 & 1 & - & - & 5 & 1 \\
\hline Optimal cost & \multicolumn{4}{|c|}{89166} & \multicolumn{4}{|c|}{89166} & \multicolumn{4}{|c|}{89166} \\
\hline CPU time & \multicolumn{4}{|c|}{0.655} & \multicolumn{4}{|c|}{1.744} & \multicolumn{4}{|c|}{2.3} \\
\hline Average iterations & \multicolumn{4}{|c|}{350} & \multicolumn{4}{|c|}{1278} & \multicolumn{4}{|c|}{3758} \\
\hline
\end{tabular}

TABLE 4: The relevant data of purchasing activities of 15-echelon model.

\begin{tabular}{|c|c|c|c|c|c|c|c|c|c|c|c|c|}
\hline \multicolumn{13}{|c|}{ Purchasing activity } \\
\hline Echelon & $D_{i}$ & $C_{s i}$ & $H_{p i}$ & $C_{e i}$ & $\beta_{i}$ & $\lambda_{L i}$ & $\gamma_{L i}$ & $\mu_{L d i}$ & $\sigma_{L d i}$ & $F_{i}$ & $X_{i}$ & $\emptyset_{i}$ \\
\hline 1 & $18 \mathrm{w}$ & 25 & 2.8 & 29 & 3.2 & 0.005 & 0.015 & 0.009 & 0.002 & 70 & 0.005 & 0.03 \\
\hline 2 & $20 \mathrm{w}$ & 28 & 2.2 & 32 & 2.6 & 0.004 & 0.01 & 0.0064 & 0.0012 & 50 & 0.003 & 0.01 \\
\hline 3 & $24 \mathrm{w}$ & 32 & 1.7 & 38 & 2.1 & 0.003 & 0.009 & 0.0054 & 0.0012 & 48 & 0.003 & 0.04 \\
\hline 4 & $30 \mathrm{w}$ & 36 & 1.2 & 42 & 1.6 & 0.004 & 0.012 & 0.0072 & 0.0016 & 55 & 0.004 & 0.05 \\
\hline 5 & $35 \mathrm{w}$ & 35 & 0.8 & 37 & 1.2 & 0.006 & 0.016 & 0.01 & 0.002 & 80 & 0.005 & 0.01 \\
\hline 6 & $40 \mathrm{w}$ & 38 & 0.6 & 40 & 0.9 & 0.004 & 0.014 & 0.008 & 0.002 & 65 & 0.005 & 0.02 \\
\hline 7 & $42 w$ & 40 & 0.5 & 28 & 1.2 & 0.005 & 0.013 & 0.01 & 0.002 & 70 & 0.005 & 0.03 \\
\hline 8 & $45 \mathrm{w}$ & 42 & 0.7 & 35 & 1.5 & 0.004 & 0.009 & 0.009 & 0.0018 & 50 & 0.004 & 0.02 \\
\hline 9 & $50 \mathrm{w}$ & 44 & 1.0 & 42 & 1.0 & 0.003 & 0.010 & 0.005 & 0.0024 & 55 & 0.004 & 0.02 \\
\hline 10 & $52 \mathrm{w}$ & 46 & 1.5 & 35 & 2.2 & 0.005 & 0.012 & 0.0062 & 0.0025 & 60 & 0.005 & 0.02 \\
\hline 11 & $56 \mathrm{w}$ & 48 & 2.0 & 49 & 2.5 & 0.006 & 0.009 & 0.01 & 0.0026 & 65 & 0.003 & 0.03 \\
\hline 12 & $60 \mathrm{w}$ & 50 & 2.2 & 40 & 1.4 & 0.004 & 0.016 & 0.012 & 0.002 & 48 & 0.005 & 0.04 \\
\hline 13 & $62 \mathrm{w}$ & 55 & 1.7 & 35 & 1.5 & 0.007 & 0.015 & 0.009 & 0.0018 & 72 & 0.004 & 0.04 \\
\hline 14 & $65 \mathrm{w}$ & 56 & 1.2 & 32 & 1.6 & 0.003 & 0.014 & 0.0078 & 0.002 & 70 & 0.006 & 0.03 \\
\hline 15 & - & - & - & - & - & - & - & - & - & - & - & - \\
\hline
\end{tabular}

TABLE 5: The relevant data of manufacturing activities of 15-echelon model.

\begin{tabular}{lccc}
\hline \multicolumn{4}{c}{ Manufacturing activities } \\
Echelon & $P_{i}$ & $C_{m i}$ & $H_{m i}$ \\
\hline 1 & - & - & - \\
2 & 200000 & 280 & 2.5 \\
3 & 240000 & 200 & 1.9 \\
4 & 300000 & 320 & 1.4 \\
5 & 350000 & 360 & 1.0 \\
6 & 400000 & 380 & 0.9 \\
7 & 450000 & 420 & 0.5 \\
8 & 480000 & 440 & 1.0 \\
9 & 500000 & 420 & 1.2 \\
10 & 520000 & 400 & 1.5 \\
11 & 540000 & 450 & 2.0 \\
12 & 580000 & 440 & 2.2 \\
13 & 620000 & 420 & 1.8 \\
14 & 640000 & 460 & 1.5 \\
15 & 660000 & 380 & 1.6 \\
\hline
\end{tabular}

receiving shipment $\emptyset_{i}$ were considered to make sensitive analysis and observe the influence on the optimal total joint cost. The defective rate and production runs were changed by $\emptyset_{i}(1+R \%)$ and $N_{m i}(1+R \%)$, where the values of $R$ are $\{0,50,100,200,300,400\}$.

Figure 5 illustrated that defective rate was more sensitive than production runs under the situation that production runs were one-time production except first echelon. In that case, the higher the defective rate was, the higher the total cost was. Accordingly, inspecting goods cautiously before delivery and reducing the defective rate would lower total cost of the whole supply chain. However, if relaxing that assumption, this sensitive analysis would result in different outcomes.

Figure 6 has shown that production runs were more sensitive than defective rate when relaxing one-time production assumption. In this case, the higher the production runs were, the higher the total cost was. Hence, reducing production runs should play an essential role in the whole supply chain. Once the one batch production policy was able to satisfy the demand from the buyer, the total cost of whole supply chain will go down extremely. 
TABLE 6: Comparisons between three ways of 15-echelon inventory model.

\begin{tabular}{|c|c|c|c|c|c|c|c|c|c|c|c|c|}
\hline \multirow[b]{2}{*}{ Echelon } & \multicolumn{4}{|c|}{ ACA } & \multicolumn{4}{|c|}{ PSO } & \multicolumn{4}{|c|}{ Lingo } \\
\hline & $N_{p i}$ & $m_{L i}$ & $K_{i}$ & $N_{m i}$ & $N_{p i}$ & $m_{L i}$ & $K_{i}$ & $N_{m i}$ & $N_{p i}$ & $m_{L i}$ & $K_{i}$ & $N_{m i}$ \\
\hline$\overline{1}$ & 1 & 0.0147 & - & - & 1 & 0.0147 & - & - & 1 & 0.0147 & - & - \\
\hline 2 & 1 & 0.00987 & 11 & 1 & 1 & 0.00987 & 11 & 1 & 1 & 0.00987 & 11 & 1 \\
\hline 3 & 1 & 0.00889 & 13 & 1 & 1 & 0.00889 & 13 & 1 & 1 & 0.00889 & 13 & 1 \\
\hline 4 & 1 & 0.01184 & 11 & 1 & 1 & 0.01184 & 11 & 1 & 1 & 0.01184 & 11 & 1 \\
\hline 5 & 1 & 0.01571 & 8 & 1 & 1 & 0.01571 & 8 & 1 & 1 & 0.01571 & 8 & 1 \\
\hline 6 & 1 & 0.01378 & 5 & 1 & 1 & 0.01378 & 5 & 1 & 1 & 0.01378 & 5 & 1 \\
\hline 7 & 1 & 0.01451 & 5 & 1 & 1 & 0.01451 & 5 & 1 & 1 & 0.01451 & 5 & 1 \\
\hline 8 & 1 & 0.01287 & 5 & 1 & 1 & 0.01287 & 5 & 1 & 1 & 0.01287 & 5 & 1 \\
\hline 9 & 1 & 0.0154 & 7 & 1 & 1 & 0.0154 & 7 & 1 & 1 & 0.0154 & 7 & 1 \\
\hline 10 & 1 & 0.01432 & 9 & 1 & 1 & 0.01432 & 9 & 1 & 1 & 0.01432 & 9 & 1 \\
\hline 11 & 1 & 0.01352 & 7 & 1 & 1 & 0.01352 & 7 & 1 & 1 & 0.01352 & 7 & 1 \\
\hline 12 & 1 & 0.0162 & 8 & 1 & 1 & 0.0162 & 8 & 1 & 1 & 0.0162 & 8 & 1 \\
\hline 13 & 1 & 0.01571 & 10 & 1 & 1 & 0.01571 & 10 & 1 & 1 & 0.01571 & 10 & 1 \\
\hline 14 & 1 & 0.01611 & 5 & 1 & 1 & 0.01611 & 5 & 1 & 1 & 0.01611 & 5 & 1 \\
\hline 15 & - & - & 5 & 1 & - & - & 5 & 1 & - & - & 5 & 1 \\
\hline Optimal cost $(\$)$ & \multicolumn{4}{|c|}{231254} & \multicolumn{4}{|c|}{231254} & \multicolumn{4}{|c|}{231254} \\
\hline CPU time (s) & \multicolumn{4}{|c|}{1.725} & \multicolumn{4}{|c|}{6.621} & \multicolumn{4}{|c|}{58.215} \\
\hline Average iterations & \multicolumn{4}{|c|}{700} & \multicolumn{4}{|c|}{2883} & \multicolumn{4}{|c|}{8241} \\
\hline
\end{tabular}

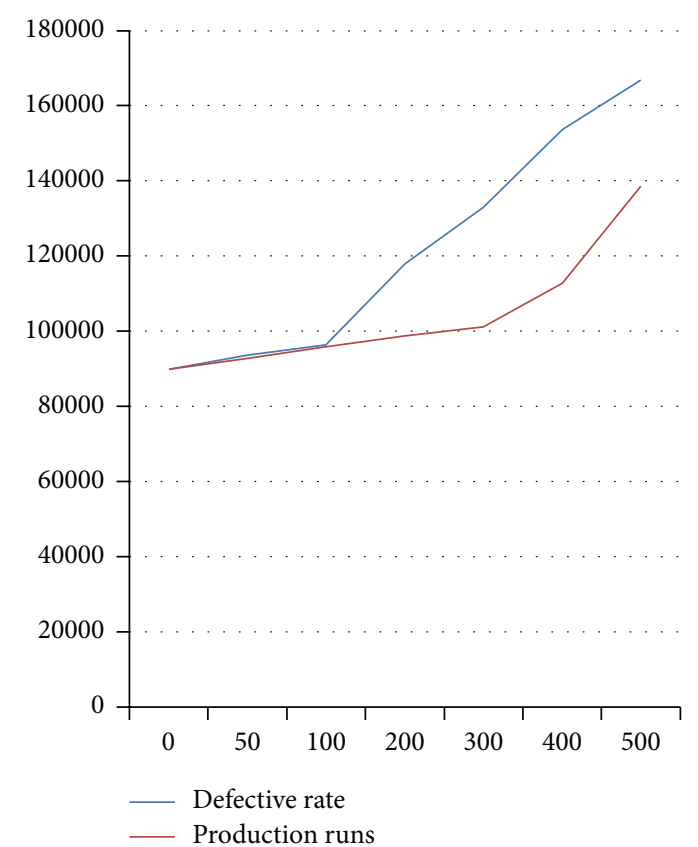

FIGURE 5: The sensitive analysis between defective rate and production runs.

\section{Conclusions}

In summary, this research proposed an integrated JIT inventory model to solve the partial optimization problem of purchaser and manufacturer, finding the optimal solution for the whole supply chain. Furthermore, a multiechelon supply chain with uncertain delivery lead time and unreliable quality has been considered to fit the real supply chain environment. Besides, ACA was proposed to solve the complicated mathematical problem; we also have proved that ACA was

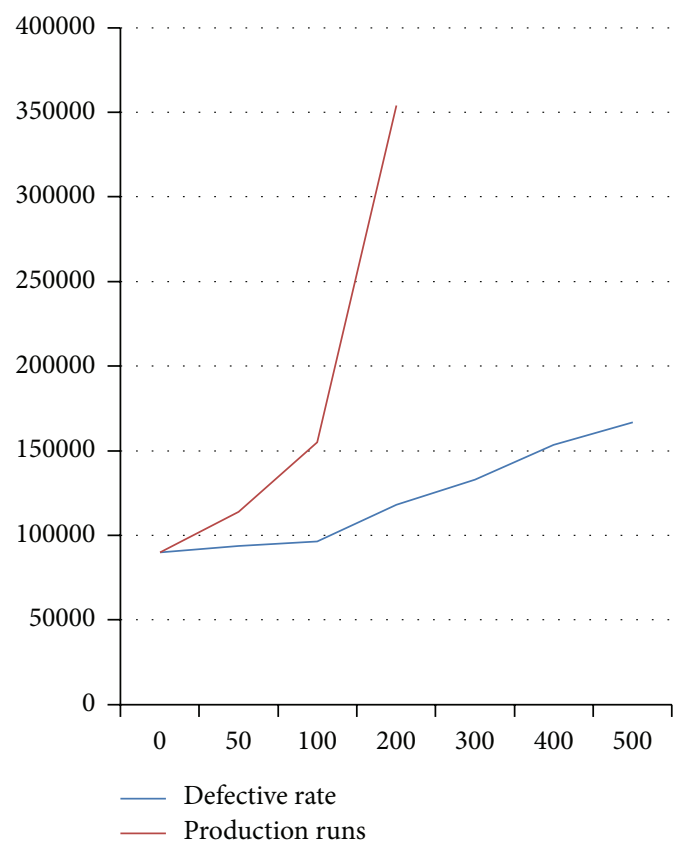

FIGURE 6: The sensitive analysis between defective rate and productions runs with relaxing assumption.

more efficient than PSO and Lingo. These are the new major contributions of the present paper.

Finally, there are a great deal of helpful directions for enterprises and researchers. (1) The variety of conditions that occur in real supply chain can be considered in the model. For instance, time value of cash problem and deterioration. (2) The warehousing and storage can be considered in supply chain, which make the model more complex to solve. (3) The model contains only one member in each echelon; a multimember in each echelon should be considered to fit 
real situation in supply chain. (4) Some real cases and/or data can be applied to our proposed model in the following works.

Future work will hopefully involve the real-world concern to our research which will be our main target. In addition, we do hope our research can be extended into more considerable areas and more considerable variables.

\section{Appendix}

The Hessian matrix $F$ of $J C_{1, S}\left(N_{p}, m_{L}, N_{m}, K\right)$ for given $N_{p i}$ equal to 1 can be shown as

$$
F=\left[\begin{array}{lll}
\frac{\partial^{2} J C_{1, S}\left(N_{m i}, m_{L i}, K_{i}\right)}{\partial N_{m i}{ }^{2}} & \frac{\partial^{2} J C_{1, S}\left(N_{m i}, m_{L i}, K_{i}\right)}{\partial N_{m i} \partial m_{L i}} & \frac{\partial^{2} J C_{1, S}\left(N_{m i}, m_{L i}, K_{i}\right)}{\partial N_{m i} \partial K_{i}} \\
\frac{\partial^{2} J C_{1, S}\left(N_{m i}, m_{L i}, K_{i}\right)}{\partial m_{L i} \partial N_{m i}} & \frac{\partial^{2} J C_{1, S}\left(N_{m i}, m_{L i}, K_{i}\right)}{\partial m_{L i}{ }^{2}} & \frac{\partial^{2} J C_{1, S}\left(N_{m i}, m_{L i}, K_{i}\right)}{\partial m_{L i} \partial K_{i}} \\
\frac{\partial^{2} J C_{1, S}\left(N_{m i}, m_{L i}, K_{i}\right)}{\partial K_{i} \partial N_{m i}} & \frac{\partial^{2} J C_{1, S}\left(N_{m i}, m_{L i}, K_{i}\right)}{\partial K_{i} \partial m_{L i}} & \frac{\partial^{2} J C_{1, S}\left(N_{m i}, m_{L i}, K_{i}\right)}{\partial K_{i}^{2}}
\end{array}\right],
$$$$
\frac{\partial^{2} J C_{1, S}\left(N_{m i}, m_{L i}, K_{i}\right)}{\partial N_{m i}^{2}}=\frac{2}{N_{m i}{ }^{3}}\left(\theta \varphi T^{2}+\frac{\varphi T^{2}(H D K \varphi / 2+\Omega)}{K}\right),
$$$$
\frac{\partial^{2} J C_{1, S}\left(N_{m i}, m_{L i}, K_{i}\right)}{\partial m_{L i}{ }^{2}}=K N\left[\left(\frac{e^{-m / \mu}}{\mu^{2}}+2\left(e^{-m / \mu}-e^{-\gamma / \mu}\right)+\frac{e^{(-m / \mu)(-m+\mu)}}{\mu}\right) v\right],
$$$$
\frac{\partial^{2} J C_{1, S}\left(N_{m i}, m_{L i}, K_{i}\right)}{\partial K_{i}^{2}}=\frac{2}{K_{i}^{3}}\left(\theta \varphi T^{2}+\frac{\varphi T^{2}(H D K \varphi / 2+\Omega)}{N}\right),
$$

$$
\frac{\partial^{2} J C_{1, s}\left(N_{m i}, m_{L i}, K_{i}\right)}{\partial m_{L i} \partial N_{m i}}=\frac{\partial^{2} J C_{1, s}\left(N_{m i}, m_{L i}, K_{i}\right)}{\partial N_{m i} \partial m_{L i}},
$$

$\frac{\partial^{2} J C_{1, S}\left(N_{m i}, m_{L i}, K_{i}\right)}{\partial K_{i} \partial N_{m i}}=\frac{\partial^{2} J C_{1, S}\left(N_{m i}, m_{L i}, K_{i}\right)}{\partial N_{m i} \partial K_{i}}$,

$\frac{\partial^{2} J C_{1, S}\left(N_{m i}, m_{L i}, K_{i}\right)}{\partial K_{i} \partial m_{L i}}=\frac{\partial^{2} J C_{1, S}\left(N_{m i}, m_{L i}, K_{i}\right)}{\partial m_{L i} \partial K_{i}}$,

$$
\left|F_{11}\right|=\frac{\partial^{2} F}{\partial N_{m i}^{2}}=\frac{2}{N_{m i}{ }^{3}}\left(\theta \varphi T^{2}+\frac{\varphi T^{2}(H D K \varphi / 2+\Omega)}{K}\right)>0,
$$$$
\left|F_{22}\right|=\left(\frac{\partial^{2} F}{\partial N_{m i}{ }^{2}}\right)\left(\frac{\partial^{2} F}{\partial m_{L i}{ }^{2}}\right)-\left[\frac{\partial^{2} F}{\partial N_{m i} \partial m_{L i}}\right]^{2}=\frac{2}{N_{m i}{ }^{3}}\left(\theta \varphi T^{2}+\frac{\varphi T^{2}(H D K \varphi / 2+\Omega)}{K}\right) \frac{\partial^{2} F}{\partial m_{L i}{ }^{2}}-\left(\frac{\partial^{2} F}{\partial N_{m i} \partial m_{L i}}\right)^{2},
$$$$
\frac{2}{N_{m i}^{3}}\left(\theta \varphi T^{2}+\frac{B}{K}\right)\left[K N\left(\frac{e^{-m \varepsilon / \mu}}{\mu^{2}}+\left(2 x+\frac{e^{(-m / \mu) x y}}{\mu} v\right)\right)\right]+K^{2}\left[\frac{e^{-m \varepsilon / \mu}}{\mu}+v(x y-A)\right]>0,
$$$$
\left|F_{33}\right|=\left(\frac{\partial^{2} F}{\partial N_{m i}^{2}} \frac{\partial^{2} F}{\partial m_{L i}^{2}} \frac{\partial^{2} F}{\partial K_{i}^{2}}\right)-\left[\left(\frac{\partial^{2} F}{\partial N_{m i} \partial K_{i}}\right)^{2}\left(\frac{\partial^{2} F}{\partial m_{L i}^{2}}\right)\right]
$$$$
=\frac{2}{N_{m i}{ }^{3}}\left(\theta \varphi T^{2}+\frac{B}{K}\right)\left[K N\left(\frac{e^{-m \varepsilon / \mu}}{\mu^{2}}+2\left(x+\frac{e^{(-m / \infty) x y}}{\mu}\right) v\right)\right] \frac{2}{K^{3}} \frac{B}{N}-\left[F+x \varepsilon+A v y-\frac{\theta \varphi T^{2}}{N^{2}}+\frac{B}{2(K N)^{2}}\right],
$$

$$
\left[K N\left(\frac{e^{-m \varepsilon / \mu}}{\mu^{2}}+\left(2 x+\frac{e^{-m \varepsilon / \mu}}{\mu}\right) v\right)\right]>0
$$


As a result, the matrix $F$ has proved to be a positive definite matrix, where $\left|F_{11}\right|,\left|F_{22}\right|$, and $\left|F_{33}\right|$ are all positive. Therefore, the minimum value exists in $J C_{1, S}\left(N_{p}, m_{L}, N_{m}, K\right)$. Furthermore, we can find the optimization in the proposed model.

\section{Competing Interests}

The authors declare that they have no competing interests.

\section{References}

[1] S. K. Goyal, "An integrated inventory model for a single supplier-single customer problem," International Journal of Production Research, vol. 15, no. 1, pp. 107-111, 1977.

[2] A. Banerjee, "A joint economic-lot-size model for purchaser and vendor," Decision Sciences, vol. 17, no. 3, pp. 292-311, 1986.

[3] S. K. Goyal, “"A joint economic-lot-size model for purchaser and vendor": a comment," Decision Sciences, vol. 19, no. 1, pp. 236-241, 1988.

[4] Y. Seo, "Controlling general multi-echelon distribution supply chains with improved reorder decision policy utilizing real-time shared stock information," Computers \& Industrial Engineering, vol. 51, no. 2, pp. 229-246, 2006.

[5] H. N. Chiu and H. L. Huang, "A Multi-echelon integrated JIT inventory model using the time buffer and emergency borrowing policies to deal with random delivery lead times," International Journal of Production Research, vol. 41, no. 13, pp. 2911-2931, 2003.

[6] J. Sadeghi, S. M. Mousavi, S. T. A. Niaki, and S. Sadeghi, "Optimizing a multi-vendor multi-retailer vendor managed inventory problem: two tuned meta-heuristic algorithms," Knowledge-Based Systems, vol. 50, pp. 159-170, 2013.

[7] S. S. Sana, "A production-inventory model of imperfect quality products in a three-layer supply chain," Decision Support Systems, vol. 50, no. 2, pp. 539-547, 2011.

[8] H. N. Soni and K. A. Patel, "Optimal strategy for an integrated inventory system involving variable production and defective items under retailer partial trade credit policy," Decision Support Systems, vol. 54, no. 1, pp. 235-247, 2012.

[9] R. J. Tersine, Principles of Inventory and Materials Management, North Holland, Amsterdam, The Netherlands, 3rd edition, 1988.

[10] C. J. Liao and C. H. Shyu, "An analytical determination of lead time with normal demand," International Journal of Operations \& Production Management, vol. 11, no. 9, pp. 72-78, 1991.

[11] M. Ben-Daya and A. Raouf, "Inventory models involving lead time as a decision variable," Journal of the Operational Research Society, vol. 45, no. 5, pp. 579-582, 1994.

[12] S. M. J. Mirzapour Al-e-Hashem, A. Baboli, and Z. Sazvar, "A stochastic aggregate production planning model in a green supply chain: considering flexible lead times, nonlinear purchase and shortage cost functions," European Journal of Operational Research, vol. 230, no. 1, pp. 26-41, 2013.

[13] C. Chandra and J. Grabis, "Inventory management with variable lead-time dependent procurement cost," Omega, vol. 36, no. 5, pp. 877-887, 2008.

[14] J.-W. Wu and H.-Y. Tsai, "Mixture inventory model with back orders and lost sales for variable lead time demand with the mixtures of normal distribution," International Journal of Systems Science. Principles and Applications of Systems and Integration, vol. 32, no. 2, pp. 259-268, 2001.
[15] M. A. Hoque, "A vendor-buyer integrated productioninventory model with normal distribution of lead time," International Journal of Production Economics, vol. 144, no. 2, pp. 409-417, 2013.

[16] F. Altiparmak, M. Gen, L. Lin, and T. Paksoy, "A genetic algorithm approach for multi-objective optimization of supply chain networks," Computers and Industrial Engineering, vol. 51, no. 1, pp. 196-215, 2006.

[17] J. Sadeghi, S. Sadeghi, and S. T. Niaki, "A hybrid vendor managed inventory and redundancy allocation optimization problem in supply chain management: an NSGA-II with tuned parameters," Computers and Operations Research, vol. 41, pp. 53-64, 2014.

[18] X. Li, F. Baki, P. Tian, and B. A. Chaouch, "A robust block-chain based tabu search algorithm for the dynamic lot sizing problem with product returns and remanufacturing," Omega, vol. 42, no. 1, pp. 75-87, 2014.

[19] Z. Chen and B. R. Sarker, "An integrated optimal inventory lot-sizing and vehicle-routing model for a multisupplier singleassembler system with JIT delivery," International Journal of Production Research, vol. 52, no. 17, pp. 5086-5114, 2014.

[20] A. R. Nia, M. Hemmati Far, and S. T. A. Niaki, "A fuzzy vendor managed inventory of multi-item economic order quantity model under shortage: an ant colony optimization algorithm," International Journal of Production Economics, vol. 155, pp. 259271, 2014.

[21] S. M. Hatefi and F. Jolai, "Robust and reliable forward-reverse logistics network design under demand uncertainty and facility disruptions," Applied Mathematical Modelling, vol. 38, no. 9-10, pp. 2630-2647, 2014.

[22] R. H. Ma, "Cross warehouse scheduling of logistics distribution and cycle re-claimer based on heuristics algorithm," Applied Mechanics and Materials, vol. 644-650, pp. 2606-2610, 2014.

[23] M. Hashim, L. Yao, A. H. Nadeem, M. Nazim, and M. Nazam, "Multi-objective optimization model for supplier selection problem in fuzzy environment," Advances in Intelligent Systems and Computing, vol. 281, pp. 1201-1213, 2014.

[24] Q.-M. Hu and Z.-H. Hu, "A stochastic programming model for hub-and-spoke network with uncertain flows," International Journal of Industrial and Systems Engineering, vol. 21, no. 3, pp. 302-319, 2015.

[25] S. A. Torabi, J. Namdar, S. M. Hatefi, and F. Jolai, "An enhanced possibilistic programming approach for reliable closed-loop supply chain network design," International Journal of Production Research, vol. 54, no. 5, pp. 1358-1387, 2016. 


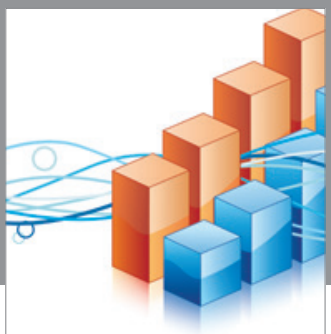

Advances in

Operations Research

vatem alat4

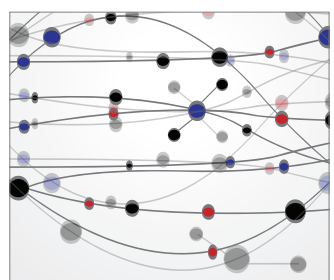

\section{The Scientific} World Journal
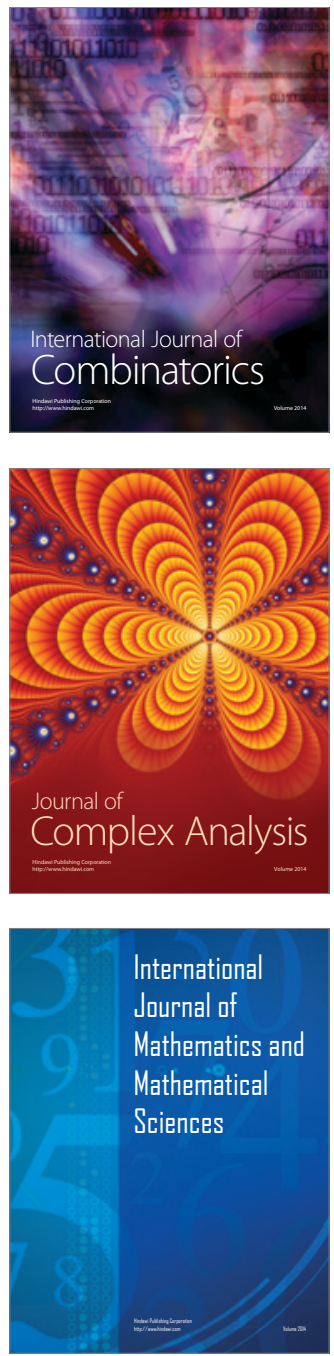
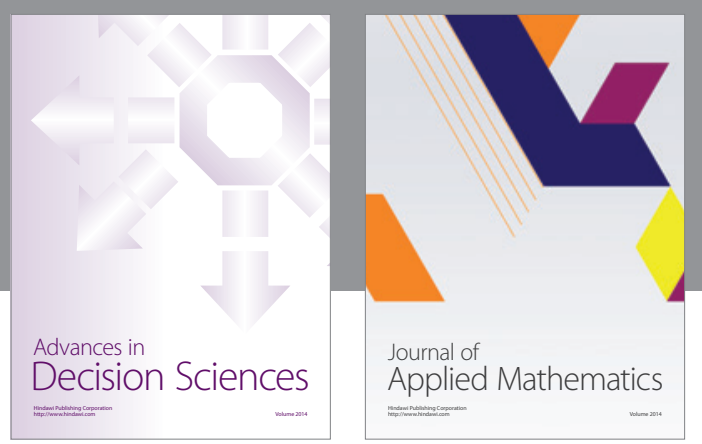

Algebra

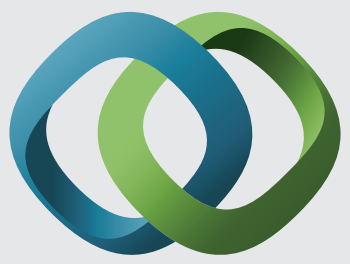

\section{Hindawi}

Submit your manuscripts at

http://www.hindawi.com
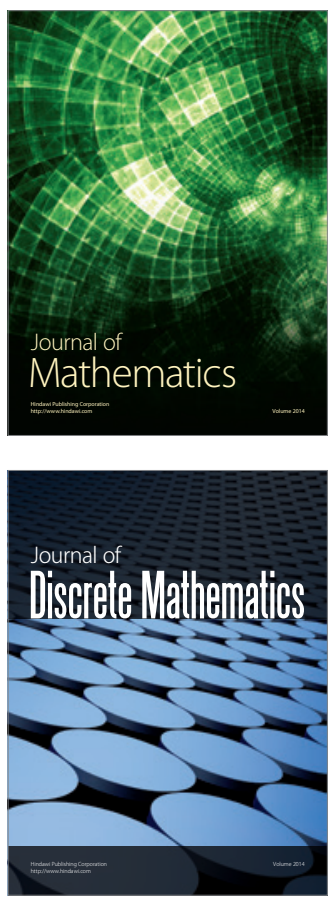

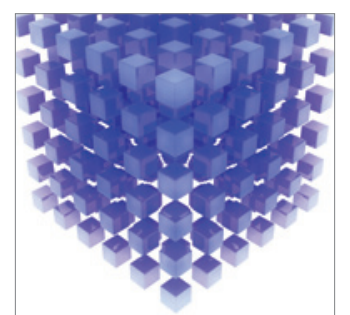

Mathematical Problems in Engineering
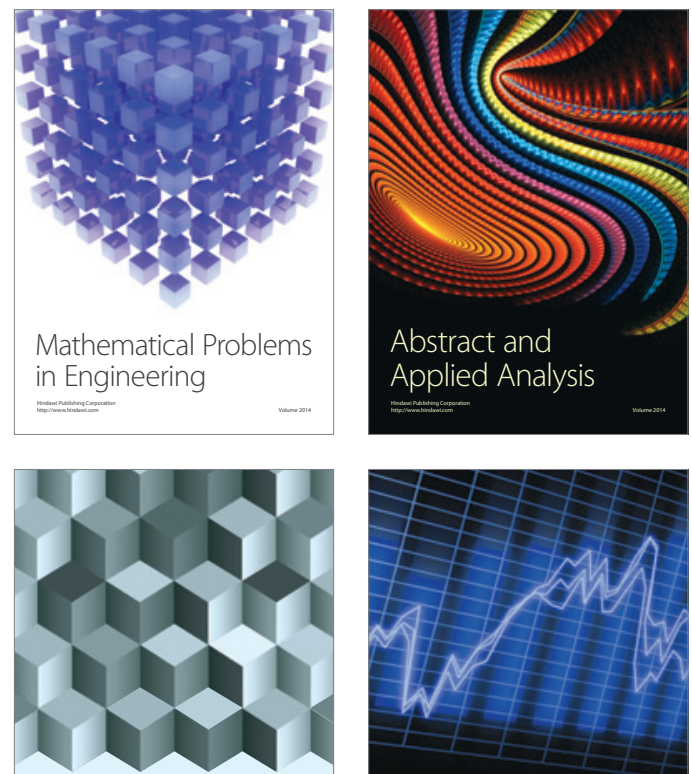

Journal of

Function Spaces

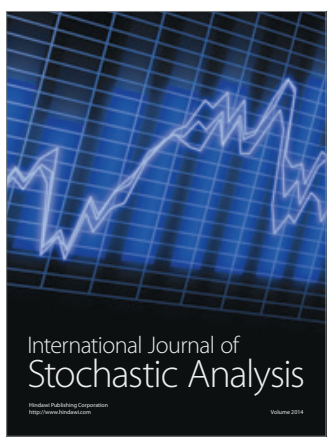

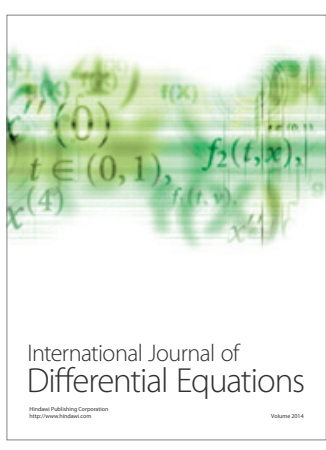
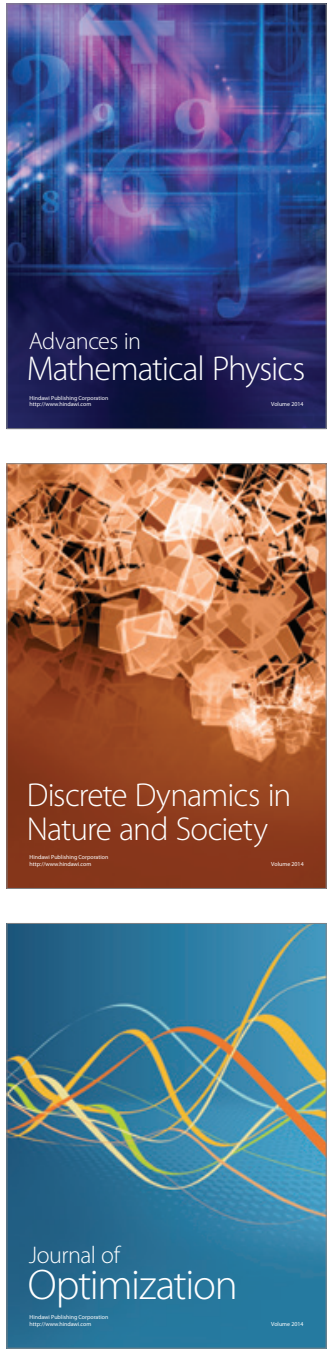